\title{
Alterations of intracellular pH homeostasis in apoptosis: origins and roles
}

\author{
D Lagadic-Gossmann ${ }^{\star,}$, L Huc $^{1}$ and V Lecureur ${ }^{1}$ \\ 1 INSERM UMR 620, Faculté des Sciences Pharmaceutiques et Biologiques, \\ Université Rennes I, 2 av Pr Léon Bernard, 35043 Rennes cedex, France \\ * Corresponding author: D Lagadic-Gossmann, INSERM UMR 620, Faculté \\ des Sciences Pharmaceutiques et Biologiques, Université Rennes I, \\ 2 av Pr Léon Bernard, 35043 Rennes cedex, France. Tel: + 33223234837 \\ Fax: + 33223234 794; E-mail: Dominique.Lagadic@rennes.inserm.fr
}

Received 07.1.04; revised 06.4.04; accepted 13.4.04; published online 11.6.04 Edited by RA Lockshin

\begin{abstract} exogenous molecules as well as, in some pathological alkalinization seems to be a common feature of proliferative processes, the precise role of $\mathrm{pH}_{\mathrm{i}}$ in apoptosis is still unclear. that merit further research in the future. Special attention is given to the possible role played by $\mathrm{pH}_{\mathrm{i}}$-regulating transporters.

Cell Death and Differentiation (2004) 11, 953-961.

doi:10.1038/sj.cdd.4401466

Published online 11 June 2004
\end{abstract}

Intracellular $\mathrm{pH}\left(\mathrm{pH}_{\mathrm{i}}\right)$ has an important role in the maintenance of normal cell function, and hence this parameter has to be tightly controlled within a narrow range, largely through the activity of transporters located at the plasma membrane. These transporters can be modulated by endogenous or situations, leading to $\mathrm{pH}_{\mathrm{i}}$ changes that have been implicated in both cell proliferation and cell death. Whereas intracellular The present review gathers the most recent advances along with previous data on both the origin and the role of $\mathrm{pH}_{\mathrm{i}}$ alterations in apoptosis and highlights the major concerns

Keywords: intracellular $\mathrm{pH}$; acidification; alkalinization; apoptosis; $\mathrm{Na}^{+} / \mathrm{H}^{+}$exchange; death receptors; mitochondria

Abbreviations: $\mathrm{pH}_{\mathrm{i}}$, intracellular $\mathrm{pH}$; $\mathrm{TNF}$, tumor necrosis factor; PTP, permeability transition pore; $\mathrm{NHE} 1, \mathrm{Na}^{+} / \mathrm{H}^{+}$exchanger 1 ; MAPK, mitogen-activated protein kinase

\section{Introduction}

Apoptosis, or programmed cell death, is a physiological process essential for normal tissue development and homeostasis. In some pathological situations, as well as in response to diverse cytotoxic exogenous molecules (xenobiotics), it also contributes to cell loss. Originally, apoptosis was first characterized by morphological changes including cell shrinkage, nuclear condensation and fragmentation, and the formation of membrane-bound cellular remnants called apoptotic bodies. Nowadays, this type of cell death is better defined by macromolecular events. In the two major apoptotic pathways known to date, that is, the 'mitochondria-dependent' pathway and the 'death receptor' pathway, activation of a family of Cysteinyl Asparte-specific Proteases (named caspases) has been recognized to play a pivotal role. When mitochondria are implicated, Bcl-2 family proteins (including $\mathrm{Bax}, \mathrm{Bid}, \mathrm{Bcl}-\mathrm{x}_{\mathrm{L}}$ ) typically regulate the release of cytochrome $c$ and other apoptogenic factors; cytochrome $c$ then interacts with Apaf-1 and procaspase 9 to form an 'apoptosome' capable of activating effector caspases such as caspase 3 . Besides these two major types of apoptosis, several cases of caspase-independent apoptosis have been reported, implicating apoptosis-inducing factor (AIF) as a determinant regulator. $^{1,2}$

In contrast, little is understood about the accompanying changes in intracellular ionic homeostasis, although there exists a certain amount of work on apoptosis-associated variations in $\mathrm{Ca}^{2+}{ }_{\mathrm{i}}, \mathrm{K}^{+}{ }_{\mathrm{i}}$ and $\mathrm{H}^{+}{ }_{\mathrm{i}}$. As the role of $\mathrm{Ca}^{2+}{ }_{\mathrm{i}}$ and $\mathrm{K}^{+}{ }_{\mathrm{i}}$ in apoptosis has been recently reviewed, ${ }^{3}$ the present review will essentially focus on $\mathrm{H}^{+}{ }_{i}$ homeostasis and will discuss recent advances in this field.

\section{Intracellular acidification in apoptosis}

The first observations of an intracellular acidification in mammalian cells undergoing apoptosis were made about a decade ago; ${ }^{4}$ since then, several reports have supported the view that this phenomenon might be a more generalized apoptotic feature than previously thought. Indeed, such an acidification (typically amounting to $0.3-0.4 \mathrm{pH}_{\mathrm{i}}$ (intracellular $\mathrm{pH}$ ) units) has been detected following exposure of cells to apoptotic stimuli as varied as UV irradiation, staurosporine, etoposide, arsenic, anti-Fas antibodies, growth factor deprivation and somatostatin (for review, see Matsuyama and Reed $^{5}$ ). In this context, it has even been proposed that the induction of an intracellular acidification using, for example, pharmacological inhibitors of the plasma membrane $\mathrm{Na}^{+} / \mathrm{H}^{+}$ antiporter might serve as a therapeutic tool for treating some types of cancer. ${ }^{6}$ Nevertheless, several important concerns remain to be more thoroughly examined: (1) What is the origin of this apoptosis-related acidification? Are alterations of $\mathrm{pH}_{\mathrm{i}^{-}}$ regulating mechanisms involved? (2) What is the exact role (initiator or activator) of this acidification in the apoptotic cascade and what are its cellular targets?

\section{Origin of apoptosis-related acidification}

Cytosolic acidification has been observed in both death receptor-mediated and mitochondria-dependent apoptosis, and has been shown to be either caspase-dependent or caspase-independent. 
Concerning the death receptor pathway, $\mathrm{pH}_{\mathrm{i}}$ changes have been studied mainly during the apoptotic events initiated following activation of the tumor necrosis factor (TNF) family receptors by Fas ligand ${ }^{7-9}$ and have been shown to occur downstream caspase activation. ${ }^{10}$ Thus, application of $\alpha C D 95$ to Jurkat cells results in a significant $\mathrm{pH}_{\mathrm{i}}$ decrease, which has been reported as soon as $1 \mathrm{~h}$ after stimulation, indicating that this phenomenon might be an early event in this type of apoptosis. ${ }^{8}$ Recently, Petit et al. ${ }^{9}$ suggested that, since this acidification was inhibited by $\mathrm{Bcl}-2$ overexpression and by both cyclosporin A and bongkrekic acid, two of the major inhibitors of the mitochondrial permeability transition pore (PTP), mitochondrial dysfunction might underlie this $\mathrm{pH}$ change. However, these organelles may not represent the sole source of protons in Fas-induced apoptosis; indeed, alterations of membrane $\mathrm{pH}_{\mathrm{i}}$-regulating mechanisms, including the $\mathrm{Na}^{+} / \mathrm{H}^{+}$exchanger (NHE), might favor accumulation of the protons produced by energetic metabolism. NHE is known to be a major carrier involved in the regulation of both cytosolic $\mathrm{pH}_{\mathrm{i}}$ and cell volume (reviewed by Putney et $a .^{11}$ ). It is affected by numerous endogenous and exogenous molecules and in diverse pathological situations; it has also been shown to play an important role in the proliferation process (reviewed by Putney et al. ${ }^{11}$ and Karmazyn et al. ${ }^{12}$ ). With respect to CD95 (Fas/Apo-1) receptor-induced apoptosis, a recent study has demonstrated that the related cytosolic acidification is partly due to inhibition of NHE. ${ }^{13}$ This inhibition was supposed to require the presence of the Src-like tyrosine kinase $\mathrm{Lck}^{56}$ since no change in $\mathrm{pH}_{\mathrm{i}}$ was observed in $\mathrm{Lck}^{56}$ deficient J-CAM1.6 cells. However, this requirement might be indirect; indeed, as the decrease in intracellular ATP level induced upon CD95 receptor triggering was absent in deficient cells, the authors then suggested that NHE inhibition would result from the decline of ATP observed upon receptor stimulation. Indeed, ATP is a well-known regulator of $\mathrm{NHE}$ activity (reviewed by Karmazyn et al. ${ }^{12}$ ). Besides kinases, phosphatases have also been implicated in the development of acidification upon Fas ligation. Thus, recruitment of the cytosolic tyrosine phosphatase SHP-1 to the membrane has been shown to be necessary for both acidification and apoptosis to occur in human breast cancer cell lines treated with Fas ligand, these phenomena being prevented by Bcl2. ${ }^{14}$ However, acidification was shown to precede mitochondrial dysfunction, thus pointing to a mitochondrion-independent effect of $\mathrm{Bcl}-2 .^{10}$ In this context, it has been suggested that the phosphatase SHP1 might downregulate the activity of $\mathrm{NHE}$ as well as that of $\mathrm{H}^{+}$-ATPase. ${ }^{14,15}$ However, if so, it remains to be determined how SHP-1 might regulate the activity of NHE, knowing that there is no site for tyrosine phosphorylation in this protein. A clue may come from the existence of the $90 \mathrm{kDa} \mathrm{Na}{ }^{+} / \mathrm{H}^{+}$exchanger 1 (NHE1) kinase (also known as p90 ${ }^{\mathrm{RSK}}$ ) that has been suggested to represent a common NHE1 regulator for diverse signaling pathways (reviewed by Karmazyn et al. $^{12}$ ) and whose activation is blocked by tyrosine kinase inhibitors. ${ }^{16}$ In this regard, it is worth noting that the phorbol ester 12-O-tetradecanoylphorbol-13-acetate (TPA) has been recently reported to rescue T lymphocytes from Fas-mediated apoptosis via activation of p90 ${ }^{\mathrm{RSK}}$, resulting in phosphorylation and inactivation of the proapoptotic protein BAD; ${ }^{17}$ moreover, TPA has long been known to induce intracellular alkalinization via NHE activation in various cells (reviewed by Putney et al. ${ }^{11}$ and Karmazyn et $a .^{12}$ ). In this context, one might then speculate that $\mathrm{p} 90^{\mathrm{RSK}}$ would be inactivated upon Fas ligation, possibly due to an SHP-1-dependent dephosphorylation step, leading to downregulation of NHE1 and hence development of acidification and apoptosis. As it has recently been demonstrated that SHP-1-dependent activation of caspase 8 precedes the decrease in $\mathrm{pH}_{\mathrm{i}},{ }^{10}$ caspase 8 might serve, in the postulated scheme, as an intermediate between SHP-1 and p90RSK or more simply between SHP-1 and NHE (Figure 1); in this regard, a cleavage of NHE1 by caspases has recently been reported. ${ }^{18}$ This hypothetical scheme has as yet to be tested experimentally. As pointed out above, although poorly studied, $\mathrm{H}^{+}$carriers other than $\mathrm{NHE}$ (such as the $\mathrm{Cl}^{-} / \mathrm{HCO}_{3}^{-}$ exchanger, $\mathrm{Na}^{+}$-dependent $\mathrm{Cl}^{-} / \mathrm{HCO}_{3}^{-}$exchanger or $\mathrm{Na}^{+}$$\mathrm{HCO}_{3}^{-}$cotransporter), as well as membrane ion channels, might also be involved in the Fas-dependent acidification; with regard to this latter point, inhibition of an outwardly rectifying chloride channel (ORCC) activated upon CD95 receptor ligation in $\mathrm{T}$ lymphocytes has thus been shown to abolish the apoptosis-related acidification. ${ }^{7}$ Clearly, the role of such transporters deserves further investigation. Moreover, it would be interesting to test the effects on $\mathrm{pH}_{\mathrm{i}}$ homeostasis of the other known ligands of the TNF family receptors, such as TNF- $\alpha$ and TRAIL (TNF-related apoptosis-inducing ligand).

In contrast to the acidification observed upon activation of the death receptor pathway, which has been shown to be caspase-dependent, the decrease in $\mathrm{pH}_{\mathrm{i}}$ elicited by mitochondria-dependent stimuli appears to be caspase-independent. Indeed, several studies have shown that broad-spectrum irreversible inhibitors of these proteases, such as the benzyloxycarbonyl-valinyl-alaninyl-aspartyl fluoromethyl ketone (zVAD), do not affect cytosolic acidification while inhibiting apoptosis. ${ }^{19-21}$ Moreover, where tested, it has been found that the acidification precedes caspase activation in cells undergoing apoptosis in response to mitochondriadependent cell death stimuli (Bax, staurosporine, UV irradiation). ${ }^{21}$ Since overexpression of $\mathrm{Bcl}-2$ was shown to prevent such an acidification, it was then proposed that mitochondria

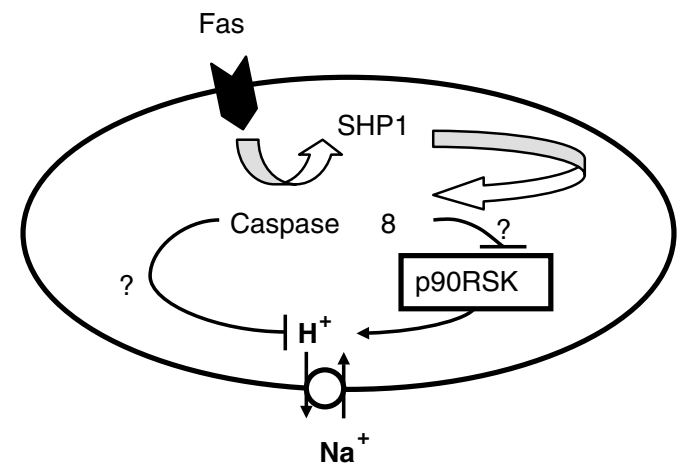

Figure 1 Hypothetical model for inhibition of $\mathrm{Na}^{+} / \mathrm{H}^{+}$exchange following activation of the Fas receptor pathway. Upon activation of Fas receptor, the tyrosine phosphatase SHP-1 would be recruited to the membrane and would trigger caspase 8 activation. ${ }^{14,15}$ Then, caspase 8 would inhibit $\mathrm{Na}^{+} / \mathrm{H}^{+}$ exchange either through a direct action or via an inhibition of the $90 \mathrm{kDa} N \mathrm{NHE} 1$ kinase (p90RSK) that is known to activate the exchange through phosphorylation (for reviews on $\mathrm{Na}^{+} / \mathrm{H}^{+}$exchange, see Putney et al. ${ }^{11}$ and Karmazyn et al. ${ }^{12}$ ) 
were responsible for this phenomenon. ${ }^{14,21,22}$ In support of this hypothesis, it has recently been demonstrated that upon diverse mitochondria-dependent apoptotic stimuli, mitochondrial alkalinization and cytosolic acidification are induced, then allowing cytochrome $c$ release and caspase activation, and that the use of $\mathrm{F}_{0} \mathrm{~F}_{1}-\mathrm{ATPase} / \mathrm{H}^{+}$pump inhibitors (such as oligomycin) prevents both $\mathrm{pH}_{\mathrm{i}}$ alterations and caspase activation. ${ }^{21}$ In this context, the authors have proposed that these changes in $\mathrm{pH}_{\mathrm{i}}$ are partially due to reverse operation of $\mathrm{F}_{0} \mathrm{~F}_{1}$-ATPase; other mechanisms such as trapping of organic bases in the mitochondrial matrix, increased exchange of $\mathrm{OH}^{-}$for $\mathrm{P}_{\mathrm{i}}$ via the mitochondrial $\mathrm{OH}^{-} / \mathrm{P}_{\mathrm{i}}$ antiporter as a result of ATP hydrolysis might also be involved (Figure 2), although yet to be demonstrated. ${ }^{5,21}$ Moreover, as described below, acidification might also result from mitochondrial ROS production. The question remains as to how reverse operation of $F_{0} F_{1}$-ATPase is triggered, especially as this scenario has been disputed by others, considering it to be thermodynamically unlikely; indeed, the presence of the proton motive force that creates a huge $\mathrm{H}^{+}$gradient in the mitochondrial matrix would hamper the reversal of the mitochondrial $\mathrm{H}^{+}$pump. ${ }^{23}$ Several hypotheses have been put forward to explain a reverse operation of the mitochondrial $\mathrm{H}^{+}$pump, including a change in the ATP/ADP ratio or an impairment of the exchange of ATP for ADP between mitochondrial matrix and cytosol. $^{21}$ In support of the latter hypothesis, it has recently been shown that, in hematopoietic cells, the cytosolic alkalinization that occurs following interleukin-3 deprivation is capable of inhibiting the mitochondrial import of ADP; under such conditions, and considering the decrease of the $\mathrm{H}^{+}$ gradient across mitochondrial membrane, a reversal of the $\mathrm{F}_{0} \mathrm{~F}_{1}$-ATPase might then occur, which would then consume ATP, pump out protons and raise the mitochondrial membrane potential $\left(\Delta \Psi_{\mathrm{m}}\right){ }^{24}$ In this context, and in an attempt to reconcile reports for and against a role for the mitochondrial

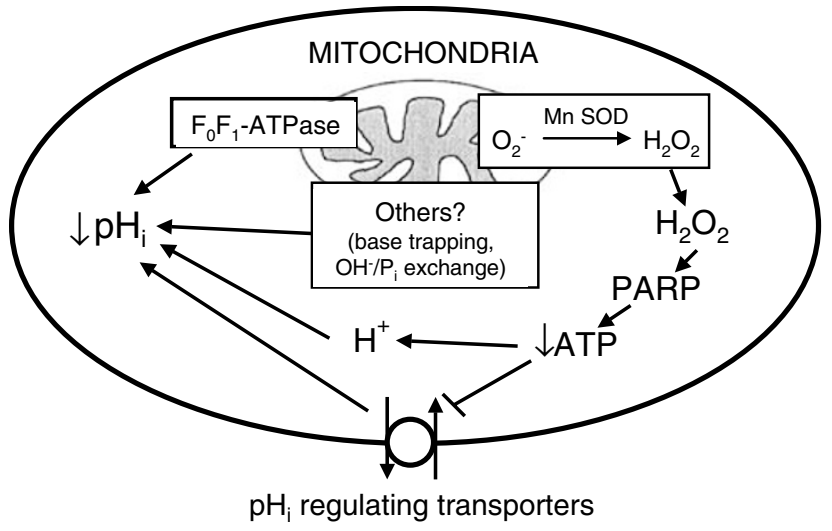

Figure 2 Involvement of mitochondria in the apoptosis-associated intracellular acidification. (a) Reversal of the mitochondrial $F_{0} F_{1}$-ATPase in the inner membrane might be responsible for cytoplasmic acidification. Other mechanisms might also be involved such as trapping of organic bases in the mitochondria matrix or increased exchange of $\mathrm{OH}^{-}$for $\mathrm{P}_{i}$ via the mitochondrial $\mathrm{OH}^{-} / \mathrm{P}_{i}$ as a result of ATP hydrolysis. ${ }^{5,21}$ Such an ATP hydrolysis, possibly resulting from $\mathrm{H}_{2} \mathrm{O}_{2}$-triggered PARP activation, ${ }^{25}$ might also result in an intracellular acid load either directly through production of $\mathrm{H}^{+}$or indirectly by affecting the activity of $\mathrm{pH}_{\mathrm{i}}$-regulating transporters $\left(\mathrm{H}_{2} \mathrm{O}_{2}\right.$ : hydrogen peroxide; MnSOD: manganese superoxide dismutase; $\mathrm{O}_{2}^{-}$: superoxide anion; PARP: poly(ADP-ribose) polymerase; $\mathrm{P}_{\mathrm{i}}$ : inorganic phosphate)

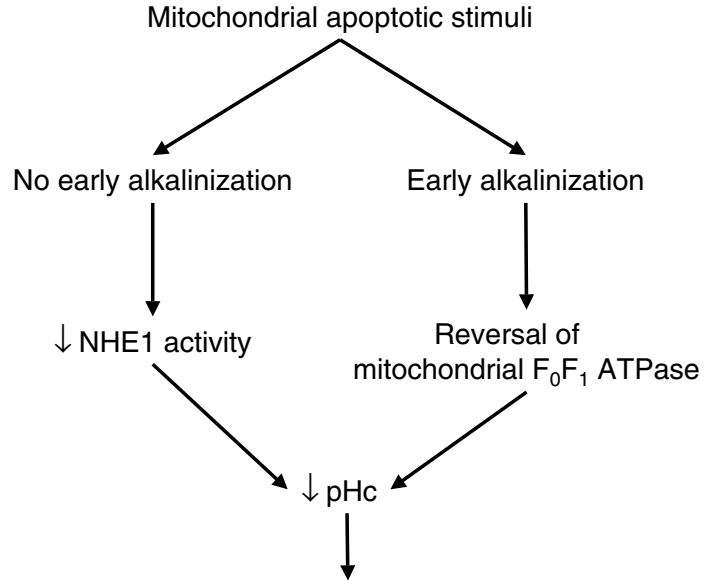

Activation of caspases, endonucleases,...

Figure 3 Hypothetical model for induction of cytoplasmic acidification following mitochondrial apoptotic stimuli. Following mitochondrial apoptotic stimuli, the decrease of the cytoplasmic $\mathrm{pH}(\mathrm{pHc})$ would result from either a downregulation of the $\mathrm{Na}^{+} / \mathrm{H}^{+}$exchange if no early cytoplasmic alkalinization occurs prior to mitochondrial targeting, or from the reversal of the mitochondrial $\mathrm{F}_{0} \mathrm{~F}_{1}$-ATPase if an early alkalinization occurs. Inspired from Matsuyama et al., ${ }^{21}$ Pervaiz and Clément $^{23}$ and Khaled et al. ${ }^{24}$

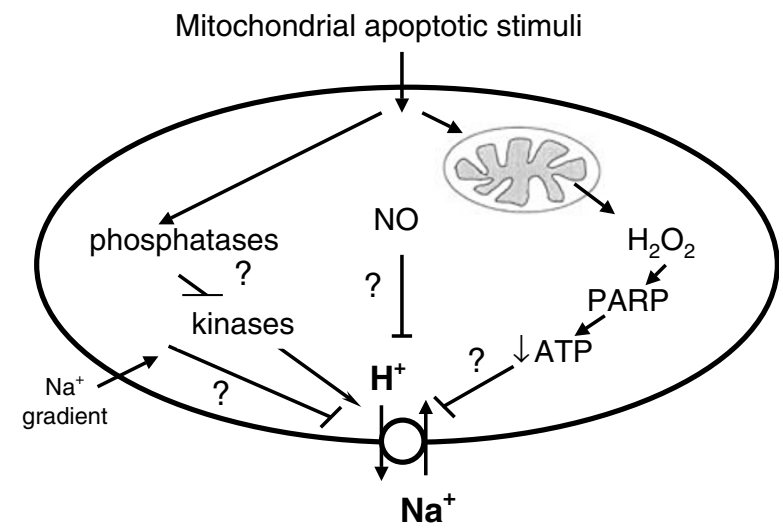

Figure 4 The different putative mechanisms for inhibition of $\mathrm{Na}^{+} / \mathrm{H}^{+}$ exchange following mitochondrial apoptotic stimuli. NO: nitric oxide; $\mathrm{H}_{2} \mathrm{O}_{2}$ : hydrogen peroxide; PARP: poly(ADP-ribose) polymerase. Inspired from Matsuyama et al., ${ }^{21}$ Hirpara et al., ${ }^{25}$ Marches et al., ${ }^{26}$ Vincent et al. ${ }^{29}$ and Koike et al. ${ }^{30}$

$\mathrm{F}_{0} \mathrm{~F}_{1}$-ATPase in the development of the apoptosis-related cytosolic acidification, one might then propose that such a role would depend upon the prior occurrence of a cytosolic alkalinization (Figure 3). In the case of no prior alkalinization, mechanisms other than this pump would then be responsible for the cytosolic acidification, as already demonstrated by several groups. Among these mechanisms, NHE has been the most commonly studied. Thus, following, for example, chemical insult ${ }^{25}$ or anti-lgM treatment, ${ }^{26}$ a decrease in NHE activity has been detected. The main factors suggested to underlie this altered activity are: (1) NHE1 dephosphorylation or (2) downregulation of NHE1 via a decrease in intracellular ATP concentration (Figure 4). Regarding the first possibility, it has recently been shown that the phosphorylation levels of the NHE1 immunoprecipitates obtained from B104 cells stimulated with an anti-IgM decreased within minutes; ${ }^{26}$ since 
cyclosporin A, used in that study as a specific inhibitor of calcineurin phosphatase, inhibited this decrease, the authors then postulated that NHE1 dephosphorylation was dependent on the action of this phosphatase. However, downregulation of NHE-controlling kinases might also be involved. With respect to the second possibility, the decrease in ATP responsible for $\mathrm{NHE} 1$ downregulation would come from the production of hydrogen peroxide $\left(\mathrm{H}_{2} \mathrm{O}_{2}\right)$ by mitochondria. In this scheme, the activation of the poly(ADP-ribose) polymerase (PARP) by $\mathrm{H}_{2} \mathrm{O}_{2}$ would play an essential role; indeed, its activation could rapidly decrease $\mathrm{NAD}^{+}$and subsequently ATP levels, thereby affecting NHE1, and this has been supported by experiments showing that prior inhibition of PARP by 3-aminobenzamide or phenanthridinone completely blocked acidification induced by $\mathrm{H}_{2} \mathrm{O}_{2} \cdot{ }^{25}$ It should nevertheless be emphasized that the way $\mathrm{pH}_{\mathrm{i}}$ varies following mitochondrial production of $\mathrm{H}_{2} \mathrm{O}_{2}$ might depend upon intracellular $\mathrm{H}_{2} \mathrm{O}_{2}$ concentration; indeed, as observed by Clément et al., ${ }^{27}$ an acidification was induced by apoptotic doses of exogenous $\mathrm{H}_{2} \mathrm{O}_{2}(0.25-0.5 \mathrm{mM})$ whereas necrotic concentrations ( $>1 \mathrm{mM}$ ) promoted intracellular alkalinization. Besides $\mathrm{H}_{2} \mathrm{O}_{2}$, other factors, such as nitric oxide, which has been shown to be proapoptotic under certain circumstances ${ }^{28}$ and to induce cytosolic acidification, for example, in neurons, ${ }^{29}$ or more simply a collapse of the sodium gradient, ${ }^{30}$ might also be involved in the downregulation of NHE activity (Figure 4); this remains as yet to be tested. In addition to NHE, it is important to stress at this point that other membrane transporters or channels as well as lactate production by glycolysis also deserve attention in the future, since they might also participate, in some situations, in the development of cytosolic acidification. Regarding membrane mechanisms, the cystic fibrosis transmembrane conductance regulator (CFTR) has recently been shown to increase lovastatin-induced apoptosis in PS120 Chinese hamster lung fibroblasts; this potentiating effect of CFTR would be through direct binding to the $\mathrm{Cl}^{-} /$ $\mathrm{HCO}_{3}^{-}$exchanger, thereby stimulating the activity of this anion exchange, which consequently leads to a further $\mathrm{pH}_{\mathrm{i}}$ decrease. ${ }^{31}$ With respect to the production of lactic acid by the glycolytic pathway, this source of intracellular $\mathrm{H}^{+}$might play an essential role in inducing apoptosis. ${ }^{32,33}$

\section{Role of the cytosolic acidification in the apoptotic cascade}

While, as mentioned previously, cytosolic acidification seems nowadays a common feature of apoptosis, its exact role in the apoptotic cascade is still a matter of debate. However, recent discoveries point to a permissive role for this $\mathrm{pH}_{\mathrm{i}}$ change in the cascade. In support of such a role, it is important to recall that, in most instances, $\mathrm{pH}$ clamping does not completely prevent cell apoptosis, suggesting that while $\mathrm{pH}_{\mathrm{i}}$ changes make important contributions, they may not be essential for apoptosis, perhaps having more to do with the kinetics rather than with the triggering phase of apoptosis. The recent paper by Affar et al. ${ }^{34}$ seems to be in agreement with this point, as these authors show that intracellular acidification, which immediately develops upon alkylating DNA damage (in contrast to apoptosis-associated acidification, which occurs much later at $2-14 \mathrm{~h}$ ), may be functioning as a negative regulator of apoptotic death in cells with damaged DNA, through a still unknown mechanism. In this context, how does cytosolic acidification facilitate the occurrence of apoptosis?

Barry and Eastman ${ }^{4,35}$ were the first to describe an endonuclease activated in intact cells when $\mathrm{pH}_{\mathrm{i}}$ reached values below $\mathrm{pH} 7.0$, independently of calcium. This endonuclease, identified as deoxyribonuclease II (DNase II) and mainly located in the nuclear fraction, has been shown to mediate internucleosomal DNA digestion characteristic of apoptosis following cytosolic acidification. Although nuclear $\mathrm{pH}$ was not measured in their studies, there was evidence suggesting that nuclear $\mathrm{pH}$ is lower than cytosolic $\mathrm{pH}$, due to the activity of a nuclear $\mathrm{H}^{+}$-ATPase. ${ }^{35}$ This protein, which appears to be identical to the proton pump mediating a $2 \mathrm{pH}$ unit gradient across the vacuolar membrane,${ }^{36}$ might induce a large acidification in the nucleus upon even limited changes of extranuclear $\mathrm{pH}$. The fact that DNase II is normally dormant and is a ubiquitous enzyme in mammalian tissues implies that its role in apoptosis-related DNA degradation would be important, especially in cells containing an important proportion of such a DNase over others and upon acidotic/apoptotic stimuli. Other low $\mathrm{pH}$-dependent endonucleases have also been identified, characterized by different molecular weights, ${ }^{37,38}$ some of which are activated by either a $\mathrm{pH}_{\mathrm{i}}$ decrease or $\mathrm{Ca}^{2+}{ }_{i}$ increase; ${ }^{39}$ another DNase II has also been located mainly in the cytoplasm as a precursor protein (namely the LEI (leucocyte elastase inhibitor)) being translocated into the nucleus following activation. ${ }^{40}$ Regarding the nuclear amount of acidic endonucleases, it is important to stress that the activity of DNase II-like 29-31 kDa polypeptides identified in fibroblasts and also that of low-pHdependent nucleases unrelated to DNase II in HL60 and HeLa cells have been shown to be upregulated upon exposure to diverse acidotic/apoptotic stimuli such as anoxia, UV or etoposide. ${ }^{37,38}$ Nonetheless, since this upregulation was not sufficient to cause any deleterious effects when caspase activation and intracellular acidification were downregulated, Famulski et al. $^{38}$ postulated that the acidic nuclease upregulation alone was not a sufficient prerequisite for the execution of apoptosis. In this context, other cellular targets for the apoptosis-related cytosolic acidification should be sought (Figure 5).

Tumor suppressors/oncogenes

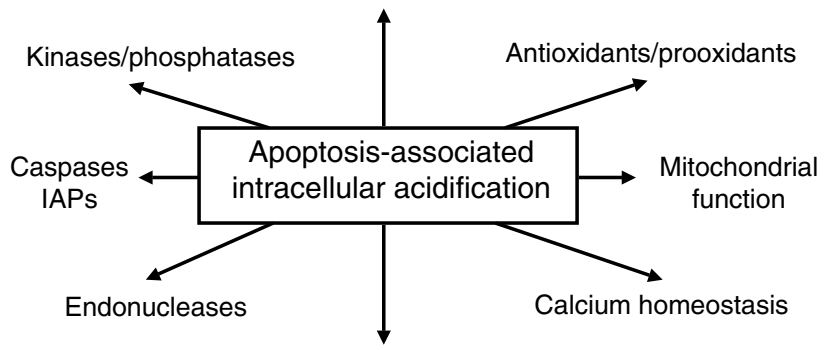

$\mathrm{Bcl}-2$ family proteins

Figure 5 Possible targets of cytoplasmic acidification following mitochondrial apoptotic stimuli. Whereas caspases, ${ }^{19,21,41,42}$ endonucleases ${ }^{4,35-40}$ and some of the Bcl-2 family proteins $5^{5,45,67}$ have been identified to be sensitive to apoptosis-associated intracellular acidosis, the other illustrated targets remain to be more thoroughly tested. IAPs: inhibitors of apoptotic proteins 
Several recent studies have clearly identified caspases as targets for cytosolic acidification. Indeed, following the work by Furlong et al. ${ }^{19}$ demonstrating that the activity of interleukin-1 $\beta$-converting enzyme (ICE)-like proteases was stimulated upon generation of a rapid $\mathrm{pH}_{\mathrm{i}}$ decrease, the $\mathrm{pH}$ sensitive caspases have been more precisely identified as cytochrome $c$-activated caspases (possibly caspase $9^{5,21}$ and caspase $3^{41,42}$ ). Regarding the former caspases, the efficiency of their activation by cytochrome $c$ has been found to exhibit a pH optimum of 6.3-6.8 in vitro and it has been suggested that assembly of the caspase activation complex (i.e. the apoptosome), consisting of oligomers of cytochrome c, Apaf-1 and procaspase 9, may occur faster at acidic $\mathrm{pH}$, although this has yet to be demonstrated. Such a $\mathrm{pH}$ dependent control might serve as a safety mechanism for avoiding inappropriate activation of cytosolic caspases, such as that caused by accidental release of small amounts of cytochrome $c$ during normal mitochondrial turnover. ${ }^{21}$ Concerning caspase 3 , such a safety mechanism effectively occurs, as it has been demonstrated that procaspase 3 dormancy is maintained by an intrinsic 'safety catch' mechanism provided by an Asp-Asp-Asp tripeptide that is removed upon acidification; under such conditions, a substantially enhanced autocatalytic maturation of procaspase 3 has been observed as well as an increased vulnerability to proteolytic activation by, for example, caspase $9 .{ }^{41}$ It is interesting to point out here that, although alkaline $\mathrm{pH}$ has been shown to inhibit activation of caspase 3 , once activated the activity of this protease remains unaffected by raising $\mathrm{pH}$ to $7.8 .^{42}$ Furthermore, these authors have shown that the repressive effect of alkalinity could be overcome with excess cytochrome $c$. Altogether, these findings suggest that the degree of caspase activation will depend on the relative importance of $\mathrm{pH}_{\mathrm{i}}$ variations and cytochrome $c$ release. However, factors such as intracellular $\mathrm{K}^{+}$concentration are also likely to be involved in this scheme. ${ }^{42}$ It is also possible that $\mathrm{pH}_{\mathrm{i}}$ could indirectly modify caspase activity by modulating the activity of endogenous caspase inhibitory proteins, such as inhibitors of apoptotic proteins (IAPs), which in humans have been shown to bind and suppress activities of caspases 9 and 3 . It is therefore worth noting that smac/Diablo, which prevents the activity of IAPs, exhibits a pl of about $5.3 .{ }^{43}$

In addition to the $\mathrm{pH}$ effects described above on caspases, changes in $\mathrm{pH}$ may also affect the functions of Bcl-2 family proteins. Since these effects have been recently reviewed, ${ }^{5}$ only the effects of acidification on Bax, BNIP3 and Mcl-1 proteins will be reported in the present review. The proapoptotic Bax proteins are known to be capable of forming pores in mitochondrial membranes, thus allowing the release of proapoptotic molecules such as cytochrome $c$, AIF and smac-Diablo. With respect to $\mathrm{pH}$, it has been reported that the channel-forming activity of Bax was eight times greater at $\mathrm{pH} 4.0$ than at $\mathrm{pH} 7.5$ and that, at physiological $\mathrm{pH}, \mathrm{Bcl}-2$ can block almost completely this pore-forming activity. ${ }^{44}$ Concerning BNIP3, a very recent report demonstrates that acidosis is necessary for this protein to induce apoptosis in hypoxic cardiac cells, likely via an effect on protein translation or stability. ${ }^{45}$ Besides an effect on protein, acidification might also control the expression of the Bcl-2 family genes; indeed, the downregulation of antiapoptotic $\mathrm{Mcl}-1$ expression, ob- served upon staurosporine treatment of MDCK cells, has been shown to be inhibited by a blocker of $\mathrm{Cl}^{-} / \mathrm{HCO}_{3}^{-}$ exchange. ${ }^{46}$ This effect is interesting as expression of $\mathrm{Mcl}-1$ in $\mathrm{CHO}$ cells has been reported to inhibit the acidification induced by staurosporine. ${ }^{47}$ In this context, one might suppose that acidification, by acting on the expression of one of its regulators, namely $\mathrm{Mcl}-1$, would further favor the execution of apoptosis. It remains to be determined how acidification controls the expression of $\mathrm{Mcl}-1$ and possibly other anti- and proapoptotic genes of the $\mathrm{Bcl}-2$ family gene.

Several other actors of the apoptotic cascade might also represent targets for cytosolic acidification, although this has been very little studied. Among these, one might cite the mitochondrion, the acidic sphingomyelinase and the p53 protein. Whereas, as previously described, apoptosis-related acidification is most commonly due to mitochondrial dysfunction, it has also been shown to occur before targeting of this organelle; in that case, the acidification might be responsible for mitochondrial dysfunction through mitochondrial membrane depolarization and release of cytochrome $c$, as shown in somatostatin-treated MCF-7 cells. ${ }^{10}$ Regarding sphingomyelinase, since it is activated at acidic $\mathrm{pH}$, its activation, as well as the consequent ceramide production, which occurs for example following caspase 8 activation during Fas-induced apoptosis, ${ }^{48}$ may be strongly enhanced following the development of intracellular acidification. Concerning p53, it has been reported that an acidic environment leads to p53dependent induction of apoptosis in human adenoma and carcinoma cell lines and that the loss of p53 function would allow cancer cells to resist such acidic conditions. ${ }^{49}$ Moreover, it has been shown that treatment of cultured neonatal rat cardiomyocytes with bafilomycin $\mathrm{A} 1$, an inhibitor of the vacuolar proton ATPase, induced an increase in both p53 protein and mRNA levels as well as intracellular acidification and apoptosis. ${ }^{50}$ In this context, one might then suppose p53 expression to be sensitive to $\mathrm{pH}_{\mathrm{i}}$ changes, although this is yet untested. The production of reactive oxygen species (ROS) has also been reported as an important determinant in the apoptotic cascade elicited by numerous stimuli and might also be a target for a decrease in cytosolic $\mathrm{pH}$. Indeed, as for the effects of ROS on $\mathrm{pH}_{\mathrm{i}}$-regulating mechanims, one might also postulate effects of $\mathrm{pH}_{\mathrm{i}}$ on the mechanisms controlling the cellular ROS concentration. In support of this, Ying et al. ${ }^{51}$ have demonstrated an increase in cell death associated with a reduction in the activities of glutathione peroxidase and glutathione $S$-transferase during exposure of murine cortical cultures to extracellular acidosis. Other signaling apoptotic pathways, such as the p38 mitogen-activated protein kinase (MAPK) pathway, might also be affected by a cytosolic acidification. ${ }^{52}$ Finally, interactions between $\mathrm{pH}_{\mathrm{i}}$ regulation and $\mathrm{Ca}_{i}^{2+}$ homeostasis might also explain the effect of cytosolic acidification; after all, it is well documented that intracellular acidification is capable of increasing $\left[\mathrm{Ca}^{2+}\right]_{i}$ in various circumstances, as shown, for example, in cardiac cells (reviewed by Karmazyn et al. ${ }^{12}$ ). Finally, in the case of some apoptotic stimuli known to be weak bases (e.g. antitumoral agents), one cannot preclude a role for intracellular acidification in the increased accumulation of the toxic drug. ${ }^{53}$ 
Intracellular alkalinization in apoptosis

Compared to intracellular acidification, only a few studies have reported an apoptosis-related intracellular alkalinization. Such a $\mathrm{pH}_{\mathrm{i}}$ change has been observed in cells undergoing situations as various as cytokine deprivation, ${ }^{54}$ gamma radiation, ${ }^{55}$ ceramide application ${ }^{56}$ and exposure to xenobiotics, such as drugs targeting proteasome, ${ }^{57}$ staurosporine, ${ }^{58}$ potassium antimonyl tartrate (PAT) ${ }^{59}$ or polycyclic aromatic hydrocarbons (PAHs). ${ }^{60}$ Therefore, it appears that such a $\mathrm{pH}_{\mathrm{i}}$ change might represent a more generalized apoptotic feature and should be looked for in a more systematic way. Besides, to our knowledge, it seems that this event is mostly encountered when the mitochondria-dependent apoptotic pathway is involved. The striking point in all these studies is that the intracellular alkalinization seems to be an early event in the apoptotic cascade, occurring prior to caspase activation and DNA fragmentation. Furthermore, when tested, this phenomenon appears to be only transient, followed ${ }^{56,60}$ or not ${ }^{54,59}$ by an intracellular acidification (i.e. reaching $\mathrm{pH}_{\mathrm{i}}$ values below control levels). The transience of apoptosisrelated alkalinization has to be stressed since a long-lasting alkaline shift of $\mathrm{pH}_{\mathrm{i}}$ is usually related to tumorigenesis. ${ }^{11}$

Regarding the origin of this alkalinization, the few data published so far point to either a plasma membrane origin via an effect upon $\mathrm{pH}_{\mathrm{i}}$-regulating transporters or to a mitochondrial origin. Among the transporters responsible for the apoptosis-related alkaline shift of $\mathrm{pH}_{\mathrm{i}}$, isoform 1 of the $\mathrm{NHE}$ would seem to be preferentially targeted, being activated for example following cytokine deprivation, ${ }^{61}$ or upon exposure to PAT (V Lecureur and D Lagadic-Gossmann, unpublished data) or toxic PAHs. ${ }^{60}$ This activation has recently been shown to result from protein phosphorylation by the p38 MAPK pathway, ${ }^{61} \mathrm{H}_{2} \mathrm{O}_{2}$ being possibly involved in such an effect. ${ }^{60}$ Regarding the involvement of ROS, it is worth noting that a role for anion superoxide has also been proposed in the NHE activation by phorbol esters; ${ }^{62}$ such a role should therefore be tested in the future. It is now well recognized that NHE1 activity is controlled by several kinases (see Putney et $a l^{11}$ for a recent review). In this context, important issues remain to be solved. (1) How do cells manage to decide between proliferation and apoptosis when an alkalinization is induced? What are the mechanisms targeted by the alkalinization responsible for such a decision? (2) What are the mechanims underlying the transient activation of NHE1 upon apoptotic stimuli? With respect to the latter issue, Khaled et al. ${ }^{61}$ have suggested that the alkaline $\mathrm{pH}_{\mathrm{i}}$ itself might secondarily inhibit the p38 MAPK pathway. Besides NHE1, a few studies have also pointed to $\mathrm{HCO}_{3}^{-}$-dependent mechanisms as being partly involved in apoptosis-related intracellular alkalinization; ${ }^{57,58}$ however, nothing is known so far about the intracellular mechanisms leading to their recruitment. Finally, activation of the mitochondrial PTP has also been suggested to lead to $\mathrm{pH}_{\mathrm{i}}$ increase following $\mathrm{C} 2$-ceramide treatment of human promyelocytic HL60 and monocytic U937 cell lines. ${ }^{56}$

The possible role of early alkalinization in the apoptotic cascade has been reported notably following application of inhibitors of $\mathrm{Na}^{+} / \mathrm{H}^{+}$exchange. Indeed, as shown for example in Figure 6 , the use of 5 -( $N$-ethyl- $N$-isopropyl)amiloride (EIPA), which inhibits a PAT-induced alkaline shift of $\mathrm{pH}_{\mathrm{i}}$ in HL60 cells, significantly reduces the percentage of apoptotic

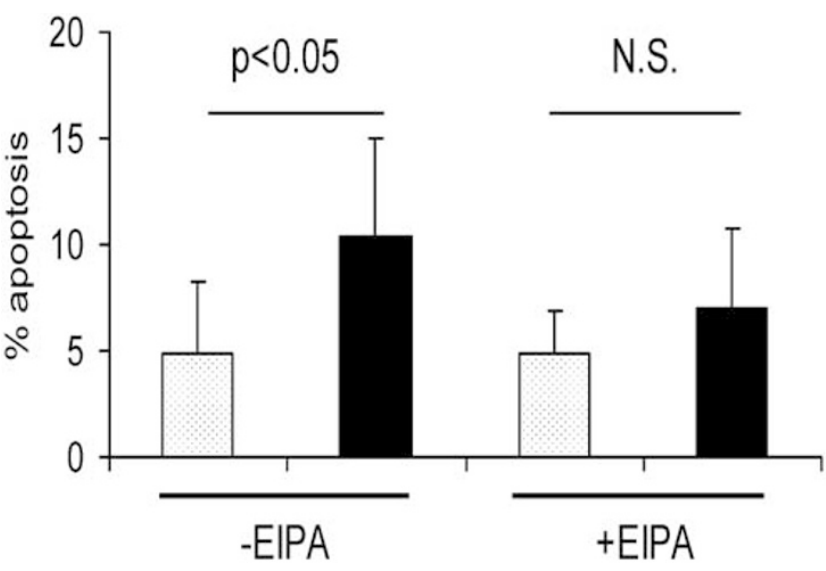

Figure 6 Effect of $\mathrm{Na}^{+} / \mathrm{H}^{+}$exchange inhibition by EIPA $(10 \mu \mathrm{M})$ on PAT $(10 \mu \mathrm{M})$-induced apoptosis in HL60 cells. Cells were either left untreated (dotted bars) or treated with $10 \mu \mathrm{M}$ of PAT (black bars) in the presence or not of EIPA $(10 \mu \mathrm{M})$ for $24 \mathrm{~h}$. Apoptosis was then estimated by Hoechst staining of nuclei. Data are the means \pm S.D. of five independent experiments. Comparison between controls and PAT-treated cells was performed using ANOVA followed by Mann-Whitney test to detect significant differences between the two groups. NS: non significant

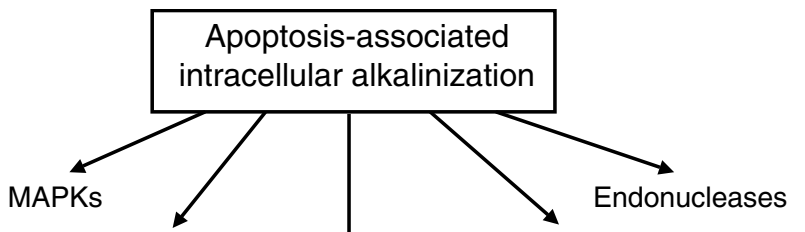

Tumor suppressors Oncogenes

$\mathrm{Bcl}-2$ family proteins

Mitochondrial ROS production

Figure 7 Putative targets of early intracellular alkalinization associated with apoptosis. Whereas endonucleases ${ }^{63-65}$ and some of the Bcl-2 family proteins ${ }^{54,56}$ have been identified to be sensitive to apoptosis-associated early intracellular alkalinization, the other illustrated targets remain to be tested. MAPKs: mitogen-activated protein kinases; ROS: reactive oxygen species

cells. In this context, early $\mathrm{pH}_{\mathrm{i}}$ alkalinization would contribute to initiation of apoptosis. It is necessary, however, to clarify NHE's exact role in the sequence of events, bearing in mind that prevention of the $\mathrm{pH}_{\mathrm{i}}$ rise generally affords only partial protection against cell death.

To date, only a few targets for intracellular alkalinization have been identified in the apoptotic cascade. Among these targets, two types of endonucleases have thus been reported, exhibiting a pH optimum of 7.5-9 and depending or not upon $\mathrm{Ca}^{2+.63-65}$ these enzymes clearly differ from DNase II in terms of optimum $\mathrm{pH}^{35}$ Besides endonucleases, the proapoptotic protein Bax appears to be another possible candidate for mediating the action of transient alkalinization. Indeed, Khaled et al. ${ }^{54}$ have shown that upon $\mathrm{pH}$ elevation this protein changes conformation, exposing membrane-seeking domains, thereby inducing mitochondrial translocation and initiating the apoptotic cascade. Such a relationship between changes in $\mathrm{Bax}$ conformation and $\mathrm{pH}_{\mathrm{i}}$ has also been reported by others, ${ }^{56}$ this being reinforced by the fact that clamping $\mathrm{pH}$ to an acidic value was shown to inhibit such conformational 
changes in Bax. ${ }^{66}$ While the mechanisms involved in mitochondrial pore formation elicited by Bax are being unraveled, those involved in mitochondrial Bax translocation are still obscure. Considering this, the early intracellular alkalinization might therefore constitute an important factor for triggering this translocation step, which is essential for Bax function. However, recent work suggests that an acidic $\mathrm{pH}_{\mathrm{i}}$ of rather large amplitude may also mediate Bax activation. ${ }^{67}$ Therefore, this point needs to be clarified, and the effects of alkalinization not only on other Bcl-2 family proteins but also on other early apoptotic events (Figure 7) need to be evaluated.

It is now well recognized that the MAPK pathways, p38 and JNK, play a major role in many apoptotic processes. However, mechanisms leading to their activation are still poorly understood. In this regard, it is worth noting that many of the substances and conditions that increase these MAPK activities have also been found to activate the NHE, thus leading to alkalinization. ${ }^{11}$ This has led Shrode et al. ${ }^{68}$ to test whether these events are causally related. Their data indicated that under some circumstances, a cytosolic alkalinization of a magnitude comparable to that attained by stimulating the antiport was sufficient to activate JNK and p38. In this context, seeking a relationship between early apoptotic alkalinization and MAPK activation deserves more attention. At last, a role for a $\mathrm{pH}_{\mathrm{i}}$ change in apoptosis-related ROS production should also be tested due to the fact that (i) alkaline-induced cell death has been shown to be prevented by expression of manganese superoxide dismutase ${ }^{69}$ and (ii) maneuvers that raise $\mathrm{pH}_{\mathrm{i}}$ potentiate oxidant production in endothelial cells. ${ }^{70}$ In this regard, preliminary results from our group point to an inhibition by cariporide (an inhibitor of NHE1) of mitochondria-dependent ROS production detected upon $\mathrm{PAH}$ exposure of liver cells. ${ }^{71}$

Finally, one should also keep in mind that $\mathrm{pH}_{\mathrm{i}}$-regulating transporters, especially NHE1, possess functions other than as $\mathrm{pH}_{\mathrm{i}}$ regulators. Thus, NHE1 has been shown to be an anchoring protein for cytoskeletal elements and to serve as a scaffolding molecule. ${ }^{11}$ At present, nothing is known about the role of such functions in apoptosis. One should also consider the role of the other ions carried by these transporters, especially $\mathrm{Na}^{+}$and $\mathrm{HCO}_{3}^{-}$ions, which have been reported to participate in apoptosis. ${ }^{72,73}$

\section{Conclusion}

On the whole, this review highlights the fact that, although a certain number of studies report $\mathrm{pH}_{\mathrm{i}}$ variations during apoptosis, much work still needs to be carried out in this field in order to answer the questions raised above. Particularly, the role of NHE1 activation in apoptosis needs to be clarified, especially as a similar NHE activation has previously been associated with cell proliferation. In the context of NHE1 activation, elucidating the molecular targets responsible for cell decision between apoptosis and proliferation is likely to be of importance in view of cancer treatment, knowing that disturbances of $\mathrm{pH}$ homeostasis (i.e. extracellular acidification and, more often, intracellular alkalinization) are a common feature of cancer$^{6}{ }^{6}$ in this way possibly hampering the apoptotic processes. Supporting this view, two recent reports need to be considered: the first has reported modulation of several anti- and proapoptotic genes upon extracellular acidification $^{74}$; the second is a novel mechanism of tumorigenesis involving a destabilization of a mutant p53 tetramer upon alkalinization. ${ }^{75}$

\section{Acknowledgements}

We wish to thank Prof. RD Vaughan-Jones (Burdon Sanderson Cardiac Science Centre, University Laboratory of Physiology, Oxford, UK) for critically reading the manuscript and for helpful discussion.

\section{References}

1. Cande C, Cohen I, Daugas E, Ravagnan L, Larochette N, Zamzami N and Kroemer G (2002) Apoptosis-inducing factor (AIF): a novel caspaseindependent death effector released from mitochondria. Biochimie 84: 215-222

2. van Gurp M, Festiens N, van Loo G, Saelens $X$ and Vandenabeele $P$ (2003) Mitochondrial intermembrane proteins in cell death. Biochem. Biophys. Res. Commun. 304: 487-497

3. Yu SP, Canzoniero LMT and Choi DW (2001) Ion homeostasis and apoptosis. Curr. Opin. Cell Biol. 13: 405-411

4. Barry MA and Eastman A (1992) Endonuclease activation during apoptosis: the role of cytosolic $\mathrm{Ca}^{2+}$ and pH. Biochem. Biophys. Res. Commun. 186: 782-789

5. Matsuyama S and Reed JC (2000) Mitochondria-dependent apoptosis and cellular $\mathrm{pH}$ regulation. Cell Death Differ. 7: 1155-1165

6. Izumi $H$, Torigoe $T$, Ishiguchi $H$, Uramoto $H$, Yoshida $Y$, Tanabe $M$, Ise $T$, Murakami T, Yoshida T, Nomoto M and Kohno K (2003) Cellular pH regulators: potentially promising molecular targets for cancer chemotherapy. Cancer Treat. Rev. 29: 541-549

7. Szabó I, Lepple-Wienhes A, Kaba KN, Zporatti M, Gulbins E and Lang F (1998) Tyrosine kinase-dependent activation of a chloride channel in CD95-induced apoptosis in T lymphocytes. Proc. Natl. Acad. Sci. USA 95: 6169-6174

8. Gottlieb RA, Nordberg J, Skowronski E and Babior BM (1996) Apoptosis induced in Jurkat cells by several agents is preceded by intracellular acidification. Proc. Natl. Acad. Sci. USA 93: 654-658

9. Petit PX, Gendron MC, Schrantz N, Metivier D, Kroemer G, Maciorowska Z, Sureau $F$ and Koester $S$ (2001) Oxidation of pyridine nucleotides during Fasand ceramide-induced apoptosis in Jurkat cells: correlation with changes in mitochondria, glutathione depletion, intracellular acidification and caspase 3 activation. Biochem. J. 353: 357-367

10. Liu D, Martino G, Thangaraju M, Sharma M, Halwani F, Shen SH, Patel YC and Srikant CB (2000) Caspase-8-mediated intracellular acidification precedes mitochondrial dysfunction in somatostatin-induced apoptosis. J. Biol. Chem. 275: 9244-9250

11. Putney LK, Denker SP and Barber DL (2002) The changing face of the $\mathrm{Na}^{+} / \mathrm{H}^{+}$ exchanger, NHE1: structure, regulation, and cellular actions. Annu. Rev. Pharmacol. Toxicol. 42: 527-552

12. Karmazyn M, Avkiran M and Fliegel L (eds) (2003) The Sodium-Hydrogen Exchanger. From Molecule to its Role in Disease. Dordrecht: Kluwer Academic Publishers, 318pp

13. Lang F, Madlung J, Bock J, Lückeville U, Kaltenbach S, Lang KS, Belka C, Wagner CA, Lang HJ, Gulbins E and Lepple-Wienhues A (2000) Inhibition of Jurkat-T-lymphocyte $\mathrm{Na}^{+} / \mathrm{H}^{+}$-exchanger by CD95 (Fas/Apo-1)-receptor stimulation. Pflügers Arch. 440: 902-907

14. Thangaraju M, Sharma K, Leber B, Andrews DW, Shen SH and Srikant CB (1999) Regulation of acidification and apoptosis by SHP-1 and Bcl-2. J. Biol. Chem. 274: 29549-29557

15. Thangaraju M, Sharma K, Liu D, Shen SH and Srikant CB (1999) Interdependent regulation of intracellular acidification and SHP-1 in apoptosis. Cancer Res. 59: 1649-1654

16. Abe J, Okuda M, Huang Q, Yoshizumi M and Berk BC (2000) Reactive oxygen species activate p90 ribosomal 66 kinase via Fyn and Ras. J. Biol. Chem. 275: $1739-1748$ 
17. Berlotto C, Maulon L, Filippa N, Baier G and Auberger P (2000) Protein kinase $\mathrm{C} \theta$ and $\varepsilon$ promote T-cell survival by a Rsk-dependent phosphorylation and inactivation of BAD. J. Biol. Chem. 47: 37246-37250

18. Wu KL, Khan S, Lakhe-Reddy S, Wang L, Jarad G, Miller RT, Konieczkowski M, Brown AM, Sedor JR and Schelling JR (2003) Renal tubular epithelial cell apoptosis is associated with caspase cleavage of the $\mathrm{NHE} 1 \mathrm{Na}^{+} / \mathrm{H}^{+}$exchanger. Am. J. Physiol. Renal Physiol. 284: F829-F839

19. Furlong IJ, Ascaso R, Lopez Rivas A and Collins MK (1997) Intracellular acidification induces apoptosis by stimulating ICE-like protease activity. J. Cell Sci. 110: 653-661

20. Zanke BW, Lee C, Arab S and Tannock IF (1998) Death of tumor cells after intracellular acidification is dependent on stress-activated protein kinases (SAPK/JNK) pathway activation and cannot be inhibited by Bcl-2 expression or interleukin 1beta-converting enzyme inhibition. Cancer Res. 58: 2801-2808

21. Matsuyama S, Llopis J, Deveraux QL, Tsien RY and Reed JC (2000) Changes in intramitochondrial and cytosolic $\mathrm{pH}$ : early events that modulate caspase activation during apoptosis. Nat. Cell Biol. 2: 318-325

22. Clément M-V, Hirpara JL and Pervaiz S (2003) Decrease in intracellular superoxide sensitizes Bcl-2-overexpressing tumor cells to receptor and druginduced apoptosis independent of the mitochondria. Cell Death Differ. 10: 1273-1285

23. Pervaiz S and Clément MV (2002) A permissive apoptotic environment: function of a decrease in intracellular superoxide anion and cytosolic acidification. Biochem. Biophys. Res. Commun. 290: 1145-1150

24. Khaled AR, Reynolds DA, Young HA, Thompson CB, Muegge K and Durum SK (2001) Interleukin-3 withdrawal induces an early increase in mitochondrial membrane potential unrelated to the Bcl-2 family. Roles of intracellular $\mathrm{pH}$, ADP transport, and F(0)F(1)-ATPase. J. Biol. Chem. 276: 6453-6462

25. Hirpara JL, Clément MV and Pervaiz S (2001) Intracellular acidification triggered by mitochondrial-derived hydrogen peroxide is an effector mechanism for drug-induced apoptosis in tumor cells. J. Biol. Chem. 276: 514-521

26. Marches R, Vitetta ES and Uhr JW (2001) A role for intracellular pH in membrane IgM-mediated cell death of human B lymphomas. Proc. Natl. Acad. Sci. USA 98: 3434-3439

27. Clément MV, Ponton A and Pervaiz S (1998) Apoptosis induced by hydrogen peroxide is mediated by decreased superoxide anion concentration and reduction of intracellular milieu. FEBS Lett. 440: 13-18

28. Chung HT, Pae HO, Choi BM, Billiar TR and Kim YM (2001) Nitric oxide as a bioregulator of apoptosis. Biochem. Biophys. Res. Commun. 282: 1075-1079

29. Vincent AM, TenBroeke M and Maiese K (1999) Neuronal intracellular pH directly mediates nitric oxide-induced programmed cell death. J. Neurobiol. 40: 171-184

30. Koike T, Tanaka S, Odal T and Ninomiya T (2000) Sodium overload through voltage-dependent $\mathrm{Na}(+)$ channels induces necrosis and apoptosis of rat superior cervical ganglion cells in vitro. Brain Res. Bull. 51: 345-355

31. Barrière $H$, Poujeol $C$, Tauc M, Blasi JM, Counillon $L$ and Poujeol $P(2001)$ CFTR modulates programmed cell death by decreasing intracellular $\mathrm{pH}$ in Chinese hamster lung fibroblasts. Am. J. Physiol. Cell Physiol. 281: C810C824

32. Tiefenthaler M, Amberger A, Bacher N, Hartmann BL, Margreiter R, Kofler R and Konwalinka G (2001) Increased lactate production follows loss of mitochondrial membrane potential during apoptosis of human leukaemia cells. Br. J. Haematol. 114: 574-580

33. Jeong D-W, Kim TS, Lee JW, Kim KT, Kim HJ, Kim I-H and Kim IY (2001) Blocking of acidosis-mediated apoptosis by a reduction of lactate dehydrogenase activity through antisense mRNA expression. Biochem. Biophys. Res. Commun. 289: 1141-1149

34. Affar B, Shah RG, Dallaire AK, Castonguay V and Shah GM (2002) Role of poly(ADP-ribose) polymerase in rapid intracellular acidification induced by alkylating DNA damage. Proc. Natl. Acad. Sci. USA 99: 245-250

35. Barry MA and Eastman A (1993) Identification of deoxyribonuclease II as an endonuclease involved in apoptosis. Arch. Biochem. Biophys. 300: 440-450

36. Galloway CJ, Dean GE, Marsh M, Rudnick G and Mellman I (1983) Acidification of macrophage and fibroblast endocytic vesicles in vitro. Proc. Natl. Acad. Sci. USA 80: 3334-3338

37. Russo CA, Weber TK, Volpe CM, Stoler DL, Petrelli NJ, Rodriguez-Bigas M, Burhans WC and Anderson GR (1995) An anoxia inducible endonuclease and enhanced DNA breakage as contributors to genomic instability in cancer. Cancer Res. 55: 1122-1128
38. Famulski KS, Macdonald D, Paterson MC and Sikora E (1999) Activation of a low pH-dependent nuclease by apoptotic agents. Cell Death Differ. 6: 281-289

39. Collins MKL, Furlong IJ, Malde P, Ascaso R, Oliver J and Lopez Rivas A (1996) An apoptotic endonuclease activated either by decreasing $\mathrm{pH}$ or by increasing calcium. J. Cell Sci. 109: 2393-2399

40. Altairac S, Zeggai S, Perani $P$, Courtois $Y$ and Torriglia A (2003) Apoptosis induced by $\mathrm{Na}(+) / H(+)$ antiport inhibition activates the LEI/L-DNase II pathway. Cell Death Differ. 10: 548-557

41. Roy S, Bayly Cl, Gareau Y, Houtzager VM, Kargman S, Keen SL, Rowland K, Seiden IM, Thornberry NA and Nicholson DW (2001) Maintenance of caspase3 proenzyme dormancy by an intrinsic 'safety catch' regulatory tripeptide. Proc. Natl. Acad. Sci. USA 98: 6132-6137

42. Segal MS and Beem E (2001) Effect of pH, ionic charge, and osmolality on cytochrome $c$-mediated caspase-3 activity. Am. J. Physiol. Cell Physiol. 281: C1196-C1204

43. Verhagen AM, Ekert PG, Pakusch M, Silke J, Connolly LM, Reid GE, Moritz RL, Simpson RJ and Vaux DL (2000) Identification of DIABLO, a mammalian protein that promotes apoptosis by binding to and antagonizing IAP proteins. Cell 102: 43-53

44. Antonsson B, Conti F, Ciavatta A, Montessuit S, Lewis S, Martinou I, Bernasconi L, Bernard A, Mermod JJ, Mazzei G, Maundrell K, Gambale F, Sadoul R and Martinou JC (1997) Inhibition of Bax channel-forming activity by Bcl-2. Science 277: 370-372

45. Kubasiak LA, Hernandez OM, Bishopric NH and Webster KA (2002) Hypoxia and acidosis activate cardiac myocyte death through the $\mathrm{Bcl}-2$ family protein BNIP3. Proc. Natl. Acad. Sci. USA 99: 12825-12830

46. Araki T, Hayashi M, Watanabe N, Kanuka H, Yoshino J, Miura M and Saruta T (2002) Down-regulation of Mcl-1 by inhibition of the PI3-K/Akt pathway is required for cell shrinkage-dependent cell death. Biochem. Biophys. Res. Commun. 290: 1275-1281

47. Reynolds JE, Li J, Craig RW and Eastman A (1996) BCL-2 and MCL-1 expression in Chinese hamster ovary cells inhibits intracellular acidification and apoptosis induced by staurosporine. Exp. Cell Res. 225: 430-436

48. Sawada M, Nakashima S, Kiyono T, Yamada J, Hara S, Nakagawa M, Shinoda $\mathrm{J}$ and Sakai N (2002) Acid sphingomyelinase activation requires caspase-8 but not p53 nor reactive oxygen species during Fas-induced apoptosis in human glioma cells. Exp. Cell Res. 273: 157-168

49. Williams AC, Collard TJ and Paraskeva C (1999) An acidic environment leads to p53 dependent induction of apoptosis in human adenoma and carcinoma cell lines: implications for clonal selection during colorectal carcinogenesis. Oncogene 18: 3199-3204

50. Long X, Crow MT, Sollott SJ, O'Neill L, Menees DS, de Lourdes Hipolito M, Boluyt MO, Asai T and Lakatta EG (1998) Enhanced expression of p53 and apoptosis induced by blockade of the vacuolar proton ATPase in cardiomyocytes. J. Clin. Invest. 101: 1453-1461

51. Ying W, Han SK, Miller JW and Swanson RA (1999) Acidosis potentiates oxidative neuronal death by multiple mechanisms. J. Neurochem. 73: 15491556

52. Curthoys NP, Tang A and Gstraunthaler $\mathrm{G}$ (2001) pH regulation of renal gene expression. Novartis Found. Symp. 240: 100-111 discussion 111-114

53. Simon S, Roy D and Schindler M (1994) Intracellular pH and the control of multidrug resistance. Proc. Natl. Acad. Sci. USA 91: 1128-1132

54. Khaled AR, Kim K, Hofmeister R, Muegge K and Durum SK (1999) Withdrawal of IL-7 induces Bax translocation from cytosol to mitochondria through a rise in intracellular pH. Proc. Natl. Acad. Sci. USA 96: 14476-14481

55. Dai HY, Tsao N, Leung WC and Lei HY (1998) Increase of intracellular pH in p53-dependent apoptosis of thymocytes induced by gamma radiation. Radiat. Res. 150: 183-189

56. Belaud-Rotureau MA, Leducq N, Macouillard Poulletier de Gannes F, Diolez P, Lacoste L, Lacombe F, Bernard P and Belloc F (2000) Early transitory rise in intracellular $\mathrm{pH}$ leads to Bax conformation change during ceramide-induced apoptosis. Apoptosis 5: 551-560

57. Kim JM, Bae HR, Park BS, Lee JM, Ahn HB, Rho JH, Yoo KW, Park WC, Rho SH, Yoon HS and Yoo YH (2003) Early mitochondrial hyperpolarization and intracellular alkalinization in lactacystin-induced apoptosis of retinal pigment epithelial cells. J. Pharmacol. Exp. Ther. 305: 474-481

58. Fujita H, Ishizaki Y, Yanagisawa A, Morita I, Murota SI and Ishikawa K (1999) Possible involvement of a chloride-bicarbonate exchanger in apoptosis of endothelial cells and cardiomyocytes. Cell Biol. Int. 23: 241-249 
59. Lecureur V, Lagadic-Gossmann D and Fardel $O$ (2002) Potassium antimony tartrate induces reactive oxygen-species-related apoptosis in human myeloid leukemic HL60 cells. Int. J. Oncol. 20: 1071-1076

60. Huc L, Sparfel L, Rissel M, Dimanche-Boitrel MT, Guillouzo A, Fardel O and Lagadic-Gossmann D (2004) Identification of $\mathrm{Na}^{+} / \mathrm{H}^{+}$exchange as a new target for toxic polycylic aromatic hydrocarbons in liver cells. FASEB J. 18 (2): 344 346 Epub 04 December 2003

61. Khaled AR, Moor AN, Li A, Kim K, Ferris DK, Muegge K, Fisher RJ, Fliegel L and Durum SK (2001) Trophic factor withdrawal: p38 mitogen-activated protein kinase activates NHE1, which induces intracellular alkalinization. Mol. Cell. Biol. 21: $7545-7557$

62. Shibanuma M, Kuroki T and Nose K (1988) Superoxide as a signal for increase in intracellular pH. J. Cell. Physiol. 136: 379-383

63. Wyllie AH, Arends MJ, Morris RG, Walker SW and Evan G (1992) The apoptosis endonuclease and its regulation. Semin. Immunol. 4: 389-397

64. Kawabata H, Anzai N, Masutani H, Hirama T, Yoshida Y and Okuma M (1993) Detection of $\mathrm{Mg}(2+)$-dependent endonuclease activity in myeloid leukemia cell nuclei capable of producing internucleosomal DNA cleavage. Biochem. Biophys. Res. Commun. 191: 247-254

65. Matsubara K, Kubota M, Adachi S, Kuwakado K, Hirota H, Wakazono Y, Akiyama $Y$ and Mikawa $H$ (1994) Different mode of cell death induced by calcium ionophore in human leukemia cell lines: possible role of constitutive endonuclease. Exp. Cell Res. 210: 19-25

66. Pryde JG, Walker A, Rossi AG, Hannah S and Haslett C (2000) Temperaturedependent arrest of neutrophil apoptosis. Failure of Bax insertion into mitochondria at 15 degrees $\mathrm{C}$ prevents the release of cytochrome $c$. J. Biol. Chem. 275: 33574-33584

67. Tafani M, Cohn JA, Karpinich NO, Rothman RJ, Russo MA and Farber JL (2003) Regulation of intracellular pH mediates Bax activation in HeLa cells treated with staurosporine or tumor necrosis factor-alpha. J. Biol. Chem. 277: 49569-49576

68. Shrode LD, Rubie EA, Woodgett JR and Grinstein S (1997) Cytosolic alkalinization increases stress-activated protein kinase/c-Jun NH2-terminal kinase (SAPK/JNK) activity and p38 mitogen-activated protein kinase activity by a calcium-independent mechanism. J. Biol. Chem. 272: 13653-13659

69. Majima HJ, Oberley TD, Furukawa K, Mattson MP, Yen HC, Szweda LI and St Clair DK (1998) Prevention of mitochondrial injury by manganese superoxide dismutase reveals a primary mechanism for alkaline-induced cell death. J. Biol. Chem. 273: 8217-8224

70. Cutaia M, Kroczynski $\mathrm{J}$ and Tollefson $\mathrm{K}$ (2002) pH-dependent oxidant production following inhibition of the mitochondrial electron transport chain in pulmonary endothelial cells. Endothelium 9: 109-121

71. Huc L, Gilot D, Gardyn C, Rissel M, Dimanche-Boitrel MT, Guillouzo A, Fardel $O$ and Lagadic-Gossmann D (2003) Apoptotic mitochondrial dysfunction induced by benzo(a)pyrene in liver epithelial cells: role of $\mathrm{p} 53$ and $\mathrm{pH}_{\mathrm{i}}$ changes. Ann. NY Acad. Sci. 1010: 167-170

72. Bortner CD and Cidlowski JA (2003) Uncoupling cell shrinkage from apoptosis reveals that $\mathrm{Na}^{+}$influx is required for volume loss during programmed cell death. J. Biol. Chem. 278: 39176-39184

73. Dong Z, Wang J and Zhong Q (2003) Postmitochondrial regulation of apoptosis by bicarbonate. Exp. Cell Res. 288: 301-312

74. Bumke MA, Neri D and Elia G (2003) Modulation of gene expression by extracellular $\mathrm{pH}$ variations in human fibroblasts: a transcriptomic and proteomic study. Proteomics 3: 675-688

75. DiGiammarino EL, Lee AS, Cadwell C, Zhang W, Bothner B, Ribeiro RC, Zambetti G and Kriwacki RW (2002) A novel mechanism of tumorigenesis involving $\mathrm{pH}$-dependent destabilization of a mutant p53 tetramer. Nat. Struct. Biol. 9: 12-16 